\title{
Tulemuslikum inseneriharidus võimekususkumuste toetamise kaudu
}

\author{
Britt Petjärv $^{\mathrm{a} 1}$, Kati Aus ${ }^{\mathrm{b}}$, Grete Arro ${ }^{\mathrm{b}}$ \\ a Tallinna Tehnikakõrgkooli humanitaar-ja majandusainete keskus \\ ${ }^{b}$ Tallinna Ülikooli haridusteaduste instituut
}

\begin{abstract}
Annotatsioon
Tööturustatistika kohaselt on inseneride nappus Eestis suur probleem. Uurides kõrgkoolist väljalangemust, selgub paraku, et just tehnilist kõrgharidust omandavate üliõpilaste seas on väljalangemus kõige suurem. Uuringud näitavad, et vaimse võimekusega seotud juurdekasvuuskumuste toetamine parandab õppijate edasijõudmist matemaatikas ning et tehnikavaldkonna üliõpilaste implitsiitsed võimekususkumused mõjutavad kõrgkooliõpingutes edasijõudmist, sealhulgas väljalangemist. Siinses artiklis võetakse vaatluse alla Tallinna Tehnikakõrgkooli esimese õppeaasta üliõpilaste $(N=270)$ uskumused võimekuse muudetavuse kohta ning muud motivatsiooni ja õpipädevusega seotud tegurid. Uuringu eesmärk on hinnata, millised õppimisega seotud aspektid ennustavad edasijõudmist inseneriõppes. Samuti uuritakse, kas lühiajalise sekkumisega on võimalik muuta õppijate mõtteviisi juurdekasvuuskumuste suunas. Eksperimentaalsest sekkumisuuringust ühe õppekava alusel õppivate esmakursuslaste seas $(N=37)$ ilmneb, et sekkumisrühma üliõpilaste mõtteviisi muutus oli positiivne ehk jäävususkumused võimekuse muudetavuse kohta muutusid nõrgemaks. See osutab vajadusele toetada õppimisprotsessi puudutavaid arusaamu süsteemselt, õpetamismetoodikasse integreerituna ning kavandada õppejõudude õpetamis- ja õppimisalaste teadmiste arendamiseks asjakohaseid koolitusi.
\end{abstract}

Võtmesõnad: implitsiitsed võimekususkumused, jäävususkumus, juurdekasvuuskumus, motivatsioon, akadeemiline edasijõudmine inseneriõppes, sekkumisuuring

Humanitaar- ja majandusainete keskus, Tallinna Tehnikakõrgkool, Pärnu mnt 62, 10135 Tallinn; britt.petjarv@tktk.ee 


\section{Sissejuhatus}

Inseneride ning teiste tehnika- ja tehnoloogiavaldkonna spetsialistide nappus on paljudes riikides probleem nii insenerkonna vananemise (Baker, Wood, Corkins, \& Krause, 2015) kui ka insenerinduse erialade lõpetajate arvu vähenemise, sh üliõpilaste väljalangemuse tõttu (Dai \& Gromley, 2014; Mamaril, 2014; Meyer \& Marx, 2014, Wilson et al., 2012). Kõrgkooliõpingute katkestamise analüüsid kinnitavad, et katkestajate määr tehnika, tootmise ja ehituse õppekavarühmas on üks kõrgeimaid (Haridussilm, s. a.; Heublein \& Schmelzer, 2018) ning enim katkestatakse õpingute esimesel aastal (Dekker, Pechenizkiy, \& Vleeshouwers, 2009; Haridussilm, s. a.). Võib arvata, et kõrgkooliõpingute katkestamiseni viib üldjuhul mitme teguri koosmõju. Oluliste teguritena on nimetatud näiteks loodus- ja täppisteaduste tulemusi varasemas kooliastmes (Eris et al., 2010; Koenig, Schen, Edwards, \& Bao, 2012; Seymour \& Hewitt, 1997) ning mitmekesiste õpistrateegiate vähest kasutusoskust (Meyer \& Marx, 2014), aga ka ebatõhusaid või puuduvaid nõustamis- ja mentorlusprogramme (Seymour \& Hewitt, 1997; Wilson et al., 2012). Eespool nimetatutele võib lisada üldisemaid motivatsiooniga seotud, sotsiaalseid, poliitilisi, institutsionaalseid või isiklikku laadi tegureid (Quinn, 2013).

Mõistmaks, kuidas inimene õpib ja kuidas õppimist tulemuslikumaks muuta, tuleb teadvustada, millised psüühilised protsessid õppimisel aset leiavad ning kuidas need käitumist mõjutavad (Dweck \& Leggett, 1988). Peale akadeemilise edasijõudmise kontekstis traditsiooniliselt oluliseks peetud erialahuvi (Mamaril, 2014), rahulolu õppekava ülesehitusega (Suhre, Jansen, \& Harskamp, 2007), akadeemilise enesetõhususe (Talsma, Schüz, Schwarzer, \& Norris, 2018) ja pingutuse suunamise (Richardson, Abraham, \& Bond, 2012) tähtsustatakse õpimotivatsiooni ja -käitumisega seotud tegurina ka õppija arusaama võimekuse muudetavusest (Burnette, O’Boyle, VanEpps, Pollack, \& Finkel, 2013). Õppija implitsiitsed võimekususkumused (implicit ability beliefs) on aluseks sellele, kuidas õppija oma arengust mõtleb, milliseid õpieesmärke seab ning mis teguritele oma õpiedu või -raskused omistab (Dweck \& Leggett, 1988). Kuigi võimekususkumuste mõju õppetöös edasijõudmisele on teaduspõhiselt tõendatud (Burnette et al., 2013) ning võimekususkumuste tähtsust on ka Eestis põhikooli kontekstis teadvustatud (Aus, Jõgi, Poom-Valickis, Eisenschmidt, \& Kikas, 2017; Vinter, Aus, \& Arro, 2019), ei ole seda teadmust Eesti üliõpilaste edasijõudmist kajastavates analüüsides seni teadaolevalt veel rakendatud.

Siinse uurimuse eesmärk on analüüsida inseneriõppe üliõpilaste implitsiitseid võimekususkumusi ja teisi varem oluliseks osutunud motivatsioonitegureid ning hinnata, millised neist ennustavad edasijõudmist inseneriõpingutes. Samuti uuritakse artiklis, kas lühiajalise sekkumisega on võimalik mõjutada tehnilist rakenduskõrgharidust pakkuva kõrgkooli üliõpilaste mõtteviisi 
juurdekasvuuskumuste suunas, nagu see on ilmnenud põhikoolis kasutatud eri sekkumisviiside korral (Blackwell, Trzesniewski, \& Dweck, 2007; Paunesku et al., 2015). Üliõpilaste edasijõudmist ja väljalangemist seletavate tegurite parem tundmine on vajalik, sest analoogsed uurimused võimaldavad kõrgharidusasutustel oma õppijate eripära paremini teadvustada ning õppimist teadlikumalt ja sihipärasemalt toetada.

\section{Uurimuse teoreetilised lähtekohad}

\section{Implitsiitsed võimekususkumused}

Uurimustes eristatakse kahte arusaama õppimisega seotud vaimsest võimekusest (implicit theories of intelligence): on neid, kes kalduvad uskuma, et intelligentsust saab pingutades ja strateegiaid vahetades arendada, ning neid, kes usuvad, et inimese vaimne võimekus on pigem kaasasündinud ja muutmatu. Kirjeldatud uskumusi seostatakse pingutamiskäitumisega. Inimesed, kes usuvad, et vaimne võimekus on sünnipärane ja muutmatu, s.t kes kalduvad jäävususkumuste (fixed mindset) poole, väldivad keerulisemaid ülesandeid, sest need võivad anda tunnistust nende $n$-ö püsivatest puudujääkidest, ja pingutust, sest ka see võib olla vähese võimekuse märk, ning annavad alla, kui ilmnevad esimesed tagasilöögid (Yeager \& Dweck, 2012). Tagasilöökide korral ollakse abitud (Dweck \& Leggett, 1988), kuna eksimises nähakse tõestust võimekuse puudumise kohta (Yeager \& Dweck, 2012). See omakorda kahandab veelgi enesetõhusust, viies otsustamatuseni oma õpikäitumise reguleerimisel ja suunamisel, samuti võib väikseimgi ebaõnnestumine mõjutada inimese usku oma võimete arendatavusse (Dweck, Chiu, \& Hong, 1995). Seevastu juurdekasvuuskumuste (growth mindset) poole kalduvate õppijate mõttelaad ja käitumine on kantud veendumusest, et vaimseid võimeid saab arendada. Keerulisemate ülesannete puhul ollakse valmis rohkem pingutama, lahendusviise vahetama või abi otsima ning tagasilöökide korral pööratakse tähelepanu nendele teguritele, mis võisid tagasilöögi põhjustada (vähene ettevalmistus, ebaõnnestunud ajaplaneerimine, puudulik õpioskus vms). Juurdekasvu- ja jäävususkumusi ei saa aga vaadelda teineteise vastandina, sest uskumused võivad olla konteksti- või õppeainepõhised (Dweck, 2015a; Dweck et al., 1995; Heslin \& VandeWalle, 2008; Yeager \& Dweck, 2012; Yeager \& Walton, 2011), ilmnedes näiteks arusaamana, et talent ja intelligentsus on kaasa sündinud, aga moraalseid ja iseloomuomadustega seotud aspekte saab mõjutada (Yeager \& Dweck, 2012). Uskumuste uurimise eesmärk pole tuvastada, kumb - kas jäävus- või juurdekasvusuunaline mõtteviis - on õigem, vaid pigem see, kuidas mõjutab kaldumine ühes või teises suunas näiteks õppimist, inimeste suhteid, emotsioone ja juhtimist (Heslin \& VandeWalle, 2008). 
Kuigi inimeste implitsiitsed uskumused võivad olla kujunenud stabiilseks, on võimalik neid siiski juurdekasvuuskumuste suunas arendada. Selleks on kasutatud eri sekkumisviise: metoodilisi eksperimente tunnustamise ja tagasisidestamise kohta (Mueller \& Dweck, 1998), töötubasid ja seminare (Blackwell et al., 2007), teemakohaseid lugemisülesandeid koos eneseabikirja koostamisega (Aronson, Fried, \& Good, 2002; Paunesku et al., 2015) ja spetsiaalset arvutimängu „Brainology“ (mindsetworks.com). Need sekkumisviisid on kutsunud esile positiivseid muutuseid õppijate mõtteviisis, mis on omakorda aidanud kaasa nende edasijõudmisele õppetöös (Blackwell et al., 2007; Paunesku et al., 2015). Sekkumisuuringute tulemusi üldistades on leitud, et kõige rohkem võidavad selles protsessis need õppijad, kelle vaimseid võimeid spetsiifilises valdkonnas on peetud pigem kasinaks ning keda on mõtteliselt paigutatud kehvemate saavutustega õppijate riskirühma (Dweck, 2015a; Paunesku et al., 2015; Rattan, Savani, Chugh, \& Dweck, 2015; Yeager et al., 2016).

\section{Akadeemiline enesetõhusus}

Üks akadeemilise edasijõudmise alustaladest on akadeemiline enesetõhusus ehk inimese enda hinnang oma suutlikkusele midagi (ära) õppida (nimetatakse ka tajutud võimekuseks) (Bandura, 1986). Akadeemiline enesetõhusus on sageli aine- või isegi ülesandespetsiifiline, mis tähendab, et õppija hinnang iseendale ja motiveeritus eri ainetes võivad olla erinevad (Marsh \& Yeung, 1998; Valentine, DuBois, \& Cooper, 2004), sõltudes nii õpitingimustest kui ka keskkonnast (vt ülevaadet Jõgi \& Aus, 2015), kuid akadeemilist enesetõhusust mõjutab ka üldine toimetulek õppimisega ja sellest tulenev rahulolu iseendaga (Valentine et al., 2004). Vähene akadeemiline enesetõhusus soodustab vältiva õpikäitumise, sh õppevõlgnevuste teket, mille tagajärjel võidakse insenerialast kui tulevasest karjäärivalikust loobuda (Baker et al., 2015). Samas näitavad uuringud, et akadeemiline enesetõhusus on insenertehniliste õppeainete hinnete oluline ennustaja, kuid see ei ole inseneri õppekava alusel õppivate üliõpilaste väljalangemist ennustav tegur (Mamaril, 2014).

\section{Erialahuvi}

Õppeprotsessi juhtimise seisukohalt on tähtis, et õppija tunneks huvi õpitava valdkonna vastu ning õppetöö tervikuna oleks huvitav ja rahuldust pakkuv (Suhre et al., 2007). Valdkonnahuvi põhjal tehakse sageli otsus inseneriteaduse õppekava alusel õppima asumiseks (Meyer, 2015), seejuures on leitud, et huvi õpitava eriala vastu on õpingutes püsimajäämise oluline ennustaja (Mamaril, 2014). Huvi mõjutab õpimotivatsiooni kaht pidi: algne suur huvi õpitava eriala või aine vastu suurendab märkimisväärselt õpimotivatsiooni, kuid 
pikemaajaline suutmatus tulla keeruliste ülesannetega toime hakkab õpihuvi järk-järgult kahandama, soodustades õppevõlgnevuste teket, pettumist inseneriteaduses ning seetõttu ka eriala vahetust (Seymour \& Hewitt, 1997).

\section{Pingutuse suunamine}

Implitsiitsed võimekususkumused kujundavad seda, mil määral õppija oma õppeprotsessi panustab ja kui palju ta on valmis õpieesmärkide täitmiseks pingutama (Dweck \& Leggett, 1988). Enesereguleeritud õppimise kontekstis hõlmab pingutuse suunamine peale kognitiivsete (info omandamine ja säilitamine) ning metakognitiivsete (õpiprotsessi jälgimine ja suunamine) õpistrateegiate kasutamise oskuse ka motivatsiooniga ja emotsioonide juhtimisega seotud aspekte (Pekrun, Goetz, Titz, \& Perry, 2002; Wolters, 1998). On leitud, et soov õppetöös pingutada on suurem, kui õppimine pakub huvi ja seda saadavad positiivsed emotsioonid (Pekrun et al., 2002) ning kui pingutust märgatakse ja tunnustatakse (Mueller \& Dweck, 1998). Lisaks ennustab pingutuse suunamine paremaid hindeid matemaatikas (Blackwell et al., 2007).

\section{Uuringu kontekst}

Eesti suurim riiklik tehnikavaldkonna rakenduskõrgkool Tallinna Tehnikakõrgkool (TTK) on üks neist haridusasutustest, mis peab kõrgharidusmaastikul konkurentsis püsimiseks vähendama üliõpilaste väljalangemust. TTK on viimaste aastate jooksul võtnud mitmeid tugimeetmeid, millega toetatakse üliõpilaste edasijõudmist õpingutes (akadeemiline ja psühholoogiline nõustamine, õppekavade ajakohastamine, e-toe loomine õppe paindlikumaks muutmiseks), kuid paratamatult tekib siinkohal küsimus, kas senistest tegevustest piisab, et vähendada katkestamise määra ja saavutada riiklikult püstitatud eesmärk (vt tabel 1).

Tabel 1. TTK vastuvõtu, Iõpetajate ja (1. õppeaasta) väljalangemuse suhtarvud 2013-2018

\begin{tabular}{|l|ccccc}
\hline Õppeaasta & $\begin{array}{c}\text { Üliõpilaste } \\
\text { koguarv }\end{array}$ & Vastuvõtt & $\begin{array}{c}\text { Lõpetajate } \\
\text { arv }\end{array}$ & $\begin{array}{c}\text { Väljalangemus \% } \\
1 . \text { õppeaastal }\end{array}$ & $\begin{array}{c}\text { Eesti } \\
\text { keskmine \% }\end{array}$ \\
\hline $\mathbf{2 0 1 3 / 1 4}$ & 2803 & 625 & 309 & 34,2 & 23,0 \\
\hline $\mathbf{2 0 1 4 / 1 5}$ & 2645 & 675 & 293 & 33,1 & 21,3 \\
\hline $\mathbf{2 0 1 5 / 1 6}$ & 2422 & 635 & 286 & 35,2 & 22,3 \\
\hline $\mathbf{2 0 1 6 / 1 7}$ & 2183 & 592 & 301 & 25,9 & 21,2 \\
\hline $\mathbf{2 0 1 7 / 1 8}$ & 2234 & 651 & 326 & 29,8 & 21,6 \\
\hline $\mathbf{2 0 2 0}$ & & & & & \\
\hline
\end{tabular}

Märkus. Allikas: Haridussilm. 
Inseneriteaduse õppekavade spetsiifikat uurides selgub, et esimesel õppeaastal, mil katkestamise määr on kõige kõrgem (Dekker et al., 2009), on rõhuasetus püsivust ja pingutust nõudvatel reaalainetel (inseneriteaduse alusained), mille läbimine võib õppuritele eri põhjustel raskusi valmistada (Meyer, 2015; Seymour \& Hewitt, 1997). Kuna on leitud, et esimese óppeaasta õpitulemuste põhjal teevad õppijad edasisi valikuid oma õpitee kohta (Hunt, 2011), on eriti tähtis uurida just esimese õppeaasta kontekstis õpingute tulemuslikkust või seda takistavaid tegureid.

Eesti kõrgkoolide senine kogemus on näidanud, et katkestamiseni viib eri põhjuste koosesinemine, sealhulgas vale erialavalik, akadeemiline edasijõudmatus, vähene ühtekuuluvus- ja seotustunne, võimetele mittevastav õpe või majanduslikud raskused (Espenberg et al., 2014). Õpingute katkestamise põhjuste väljaselgitamiseks tehtud rakenduskõrghariduse uuringus, kus osales üheksa rakenduskõrgkooli, ilmnesid sagedasimate põhjustena õppevõlgnevused, omal soovil lahkumine (põhjused täpsustamata), õppetööle ilmumata jätmine ja vale erialavalik (Üliõpilaste õpingute katkestamiste ..., 2015). Paraku olid ka uuringu autorid ise sunnitud tõdema, et õpingute katkestamise põhjuste fikseerimine kirjeldatud viisil ei anna võimalust hilisemaks süvaanalüüsiks, kuna dokumenteeritud põhjuse (nt õppevõlgnevused) taga on omakorda nende tekkimise ajend, mida senine info ei võimalda analüüsida (ibid.).

Et mitmekesistada metoodikat, mille abil uurida kõrgkooliõpingutes edasijõudmist, on siinse artikli fookusesse seatud implitsiitsed võimekususkumused kui üliõpilaste õpikäitumise kujundajad, mida artikli autoritele teadaolevalt on kõrghariduse kontekstis vähe uuritud. Uurimuse eesmärk on leida, millised interaktsioonilised seosed on üliõpilaste implitsiitsete võimekususkumuste ja teiste motivatsioonitegurite kui õpitulemuste ennustajate vahel. Varasemad uurimused on näidanud, et juurdekasvuuskumused ennustavad paremaid matemaatikahindeid (Blackwell et al., 2007) ja tõhusamat edasijõudmist tehnikavaldkonna erialadel (Dai \& Cromley, 2014). Seetõttu võib eeldada, et sekkumise tulemusel ilmneb positiivne muutus õpimotivatsiooniga seotud tegurites sekkumis-, kuid mitte kontrollrühma korral (vt Aronson et al., 2002; Paunesku et al., 2015).

Kirjeldatud uurimistulemustele tuginedes püstitati järgmised hüpoteesid:

1) tehnikakõrgkooli esimese õppeaasta üliõpilaste jäävususkumused ja vähene pingutuse suunamine ennustavad halvemat ning suurem akadeemiline enesetõhusus ja erialahuvi paremat edasijõudmist reaalainetes;

2) implitsiitseid võimekususkumusi käsitleva sekkumisega on võimalik positiivselt mõjutada tehnikavaldkonna üliõpilaste implitsiitseid võimekususkumusi ja pingutuse suunamist. 


\section{Metoodika}

\section{Valim ja protseduur}

\section{Valim}

Uuringu valim koosnes 270st Tallinna Tehnikakõrgkooli üliõpilasest, kes õppisid kümne õppekava alusel. Valimist moodustasid mehed 75\% ja naised 25\%.

Sekkumisuuringu valim koosnes sama kõrgkooli ühe õppekava (edaspidi: õppekava X) alusel päevaõppes õppivatest esimese kursuse üliõpilastest. Õppekava $\mathrm{X}$ valiti välja seetõttu, et viimastel aastatel on selle õppekava alusel õppinud esmakursuslaste väljalangemise protsent olnud TTK õppeinfosüsteemi järgi üks kõrgemaid. Valimisse kuulunud üliõpilasi küsitleti kahel korral: enne ja pärast sekkumist. Esimene andmekogumine toimus 2017/18. õppeaasta oktoobris, mil kirjalikule küsimustikule vastas 46 üliõpilast. Teine andmekogumine leidis aset sekkumisuuringu järel sama aasta novembris ning sel korral oli sekkumistegevuses osalenud üliõpilaste ankeete kokku 37. Kõik vastajad olid meessoost ja vanuses 18-22. Vastanute keskmine vanus oli 19,7. Kõik üliõpilased olid uuringusse kaasamise hetkel TTK sügissemestri õppetöös osalenud ca 2 kuud.

Kontrollrühmana osalesid uuringus Tallinna Tehnikakõrgkooli päevaõppe esimese kursuse üliópilased, kes õppisid õppekava Y alusel ja kelle õppekava parameetrid olid kõige ligilähedasemad sekkumisrühma õppekava omadele: 1) kattuv sügissemestri inseneriteaduse alusainete moodul; 2) sarnases suurusjärgus vastuvõtt päevaõppes ning 3) esimeselt kursuselt väljalangemise protsent (varasema kahe õppeaasta põhjal sageduselt järgmine). Kontrollrühma kuulunud üliõpilasi küsitleti samuti kahel korral (oktoobris ja novembris). Kontrollrühma üliõpilasi osales esimeses andmekorjes 34 (28 meest ja 6 naist) ning sekkumisrühma omi 26 (20 meest ja 6 naist). Vastanud olid vanuses 19-23 (keskmine vanus 20,1 aastat).

\section{Sekkumisuuringu korraldus}

Uuringus osalenud sekkumisrühma üliõpilastele tehti kaks nädalat pärast esimest testimist sekkumine. Sekkumisviisi valikul lähtuti targa sekkumise (wise intervention) meetodist, mille puhul keskendutakse ühele konkreetsele, praeguses kontekstis tõenduspõhiselt olulisele psüühilisele protsessile (nt võimekususkumused) eesmärgiga seda muuta (Walton, 2014, ülevaatlikult vt ka Kok et al., 2016). Haridusvaldkonnas on selle meetodi abil edukalt juurutatud näiteks juurdekasvuuskumuste suunalist mõtteviisi, mille kohaselt on vaimne võimekus muudetav (Aronson et al., 2002; Blackwell et al., 2007). Sekkumise tööriistaks on sageli lihtne ja lühike harjutus (või toiming), mis on osa sekkumisrühma 
kuuluvate inimeste igapäevaelust ning mis aitab neil suunatud tegevuse kaudu muuta oma mõtteviisi või harjumusi, et seeläbi parandada tulemuslikkust või emotsionaalset või füüsilist heaolu. Et meetod toimiks, tuleb välja selgitada psüühiline protsess, mis on muudetava käitumise alus. Oluline on, et muutusest saadav kasu oleks sihtrühmale relevantne ning sekkumismetoodika oleks kohandatud kontekstiga. (Walton, 2014)

Toimunud sekkumine seisnes 90 minuti pikkuse töötoa korraldamises ainekursusel „Sissejuhatus erialasse“, et juhtida üliõpilaste tähelepanu uskumuste rollile õppimises ja tugevdada nende juurdekasvuuskumuste suunalist mõtteviisi. Töötoale eelnes üliõpilaste iseseisev töö, mille raames vaatasid õppijad intervjuud „The Growth Mindset" võimekususkumuste teooria alusepanija, Stanfordi Ülikooli psühholoogiaprofessori Carol Dweckiga (2015b) ning analüüsisid uskumuste ja õppimise seost suunavate küsimuste abil (nt Too intervjuu põhjal välja mõned aspektid, mis motiveerivad õppimisel? Mis iseloomustab eri tü̈̈pi óppijaid? Miks öeldakse, et talendi roll on üle tähtsustatud? Milliseid uskumusteteemalisi uuringuid on läbi viidud ning milliste tulemustega? Kas on midagi, millega Sa video põhjal ei nõustu? Millised on Sinu uskumused võimekuse kohta ning kuidas oled kujunenud niimoodi arvama?).

Töötoas tutvustati üliõpilastele võimekususkumuste teooriat, aju rolli õppimisel ja õpikeskkonda kujundavaid aspekte (uue info edastamine) ning julgustati õppijaid nendel teemadel arutlema (varasema ópikogemusega seostamine) ja argumenteerima (óppijate juhtimine soovitud muutuse suunas). Juurdekasvuuskumuste suunalise mõtteviisi tugevdamiseks selgitati õppijatele, et ei ole asjakohane rõhutada sünnipäraste talentide olemasolu, sest iga suurepärase saavutuse taga on olnud pingutus, järjepidev töö ning arusaam, et eksimine pole märk valdkonna sobimatusest, vaid õppeprotsessi loomulik osa. Teadvustamaks, et kõik inimesed on olenemata valdkonnast õpi- ja arenemisvõimelised, peatuti põgusalt sellel, kuidas õppimine neuronaalsel tasandil aset leiab. Sekkumisseminari järel said õppijad veel ühe iseseisva ülesande, kus neil paluti kahe nädala jooksul märgata olukordi, milles avalduvad õppuri ja teda ümbritsevate inimeste (pere, sõprade, kursusekaaslaste) juurdekasvu- või jäävususkumused, ning tulemused lühidalt kirja panna. Kahe nädala möödumisel toimus seminar, kus üliõpilased said märkamisülesande üle reflekteerida ning seostada oma seniseid teadmisi sekkumise käigus saadud infoga. Seejärel testiti uuringus osalenud üliõpilasi sama küsimustiku alusel uuesti.

\section{Mõõtevahend}

Üliõpilastel paluti enne ja pärast sekkumist vastata küsimustikule, millega selgitati välja õpimotivatsiooni ja -käitumisega seotud tegurid. Siinses uuringus 
keskendutakse vaid neile teguritele, mida võib varasemate uurimuste põhjal pidada akadeemilise edasijõudmise oluliseks ennustajaks, kuid mille omavahelisi seoseid akadeemilise edasijõudmise ennustamisel pole sellisel moel kõrghariduse kontekstis uuritud.

Implitsiitseid uskumusi võimekuse muudetavuse kohta kontrolliti alguses üheksa väitega, mis puudutasid vaimse võimekuse ja õppimisvõime olemust ning muudetavust (Dweck et al., 1995; Schommer-Aikins, Mau, Brookhart, \& Hutter, 2000). Varem projekti „Üldpädevused ja nende hindamine“ (20112014, projekti number S10012) raames tõlgitud väiteid kohandati vajaduse korral kõrgkooli konteksti järgi. Õppijad hindasid väiteid viiepunktisel skaalal ( 1 = pole üldse nõus; 5 = olen täiesti nõus). Faktoranalüüsi tulemusel otsustati skaalasse jätta vaid kolm väidet („Õppimise edukus sõltub pigem kaasasündinud võimekusest kui millestki muust“, „Tõeliselt targad inimesed ei pea palju pingutama“, „Tõeliselt targad inimesed saavad uue materjali selgeks vaeva nägemata") ning lõpliku skaala sisereliaabluse koefitsient (Cronbachi $\alpha$ ) oli 0,63.

Akadeemilist enesetõhusust hinnati nelja enesekohase väitega, mis pärinesid MSLQ-küsimustikust (motivated strategies for learning questionnaire; vt Pintrich, Smith, Garcia, \& McKeachie, 1991). Varem projekti „Üldpädevused ja nende hindamine" (2011-2014, projekti number S10012) raames tõlgitud väiteid kohandati kõrgkooli konteksti tarbeks (nt „Kui püüan, olen võimeline omandama ka kõige nõudlikuma ainekursuse sisu"). Õppijad hindasid väiteid viiepunktisel skaalal ( 1 = pole üldse nõus; 5 = olen täiesti nõus $)$ ning skaala sisereliaabluse koefitsient (Cronbachi $\alpha$ ) oli 0,69.

Erialahuvi ehk huvi inseneriteaduse vastu hinnati seitsme enesekohase väitega (nt „Inseneeria valdkond on mulle põnev“; vt Li, McCoach, Swaminathan, \& Tang, 2008). Õppijad hindasid väiteid viiepunktisel skaalal ( $1=$ pole üldse nõus; 5 = olen täiesti nõus). Erialahuvi faktorisse laadusid aktsepteeritavalt kolm väidet ning skaala Cronbachi $\alpha$ oli 0,71 .

Vähene pingutuse suunamine oli seotud kolme väitega (nt „Kui õpitav keeruliseks muutub, annan ma alla ja õpin ära ainult lihtsamad osad"), mis moodustati MSLQ-küsimustiku põhjal ja mida kasutati eestindatud projektis „Üldpädevused ja nende hindamine“ (2011-2014; projekti number S10012). Skaala sisereliaabluse koefitsient (Cronbachi $\alpha$ ) oli 0,70.

Akadeemilist edasijõudmist hinnati üliõpilaste sügissemestri reaalainete keskmise hindega (hinne 1 = kasin; hinne 5 = suurepärane; hinne $0=$ puudulik, hindamisele mitteilmumine). Sekkumisrühma reaalained olid „Matemaatika I“, „Füüsika I“ ja „Kujutav geomeetria“, kontrollrühmal aga „Matemaatika I“, „Füüsika I“ ja „Insenerigraafika“. Reaalainete programmi erinevust ainekursuste „Kujutav geomeetria“ ja „Insenerigraafika“ puhul tasandab asjaolu, et aineid õpetas sama õppejõud ning mõlemal juhul oli tegu joonestusliku ainega. 


\section{Andmeanalüïs}

Andmeanalüüsis kasutati programmi SPSS. Esimese andmekorje $(N=270)$ põhjal tehti kõigi skaaladega faktoranalüüs, millele tuginedes arvutati välja küsimustikus kasutatud alaskaalade koondskoorid. Skaalade sisereliaablust hinnati Cronbachi alfaga ning skaalade valiidsust kontrolliti alaskaalade omavaheliste seoste analüüsiga. Akadeemilist edasijõudmist ennustavaid tegureid hinnati astmelise regressioonanalüüsiga. Sekkumisuuringu tulemuste analüüsimisel kasutati keskmiste võrdlemiseks kordusmõõtmistega dispersioonanalüüsi (repeated measures ANOVA).

\section{Tulemused}

\section{Sekkumiseelsed analüïsid}

Kõigi hinnatud alaskaalade kirjeldavad statistikud ja tunnustevahelised korrelatsioonid on esitatud tabelis 2 .

Tabel 2. Hinnatud tunnuste kirjeldavad statistikud ja tunnustevahelised korrelatsioonid

\begin{tabular}{|c|c|c|c|c|c|c|c|c|}
\hline Tunnus & Min & Max & $M$ & $S D$ & 1 & 2 & 3 & 4 \\
\hline $\begin{array}{l}\text { 1. Jäävususkumus } \\
\text { vaimse võimekuse } \\
\text { muudetavuse kohta }\end{array}$ & 1 & 5 & 2,63 & 0,74 & - & & & \\
\hline $\begin{array}{l}\text { 2. Akadeemiline } \\
\text { enesetõhusus }\end{array}$ & 1,75 & 5 & 3,39 & 0,66 & $-0,18^{* *}$ & $-0,19^{* *}$ & - & \\
\hline 3. Erialahuvi & 1 & 5 & 4,02 & 0,83 & $-0,07$ & $-0,05$ & $0,35^{* *}$ & - \\
\hline $\begin{array}{l}\text { 4. Vähene pingutuse } \\
\text { suunamine }\end{array}$ & 1 & 4,33 & 2,37 & 0,82 & $0,22^{* *}$ & $0,19^{* *}$ & $-0,41^{* *}$ & $-0,21^{* *}$ \\
\hline
\end{tabular}

Märkus. ${ }^{* *}-p<0,01$.

Tunnustevahelised korrelatsioonid olid ootuspärased ning statistiliselt olulised seosed ilmnesid peale erialahuvi ja jäävususkumuste kõigi tegurite vahel.

\section{Motivatsioonitegurite seosed akadeemilise edasijõudmisega}

Et hinnata, millised õpimotivatsiooni ja -käitumisega seotud tegurid olid olulised reaalainetes edasijõudmise varieeruvuse seletajad, tehti hierarhiline lineaarne regressioonanalüüs (vt tabel 3). Analüüsis kasutati sekkumis- ja kontrollrühma $(N=63)$ sügissemestri reaalainete keskmiseid hindeid ning testis kasutati viimase andmekorje tulemusi, kuna need olid ajaliselt kõige lähemal 
talvisele eksamisessioonile. Reaalainete hindeid ennustav lõplik regressioonimudel oli statistiliselt oluline $\left(R^{2}=0,26, F(4,57)=5,09, p=0,001\right)$. Seega seletasid mudelisse kaasatud tunnused reaalainete hinnete variatiivsusest kokku $7 \%$ ning uuritud tunnustest ennustasid reaalainete hindeid kõige tugevamalt akadeemiline enesetõhusus ( $\beta=0,34, p<0,01)$, implitsiitsed võimekususkumused $(\beta=0,22, p<0,05)$ ja vähene pingutuse suunamine $(\beta=-0,26, p<0,05)$. Huvi kui hinnete ennustaja roll ei olnud statistiliselt oluline.

Tabel 3. Hierarhilise regressioonanalüüsi tulemused reaalainete keskmise hinde ennustamisel

\begin{tabular}{|c|c|c|c|c|}
\hline Tunnus & $\beta$ & $T$ & $R^{2}$ & $\Delta R^{2}$ \\
\hline Samm 1 & & & 0,05 & 0,05 \\
\hline Jäävususkumus & 0,22 & 1,77 & & \\
\hline Samm 2 & & & 0,19 & 0,14 \\
\hline Jäävususkumus & 0,27 & $2,24^{*}$ & & \\
\hline Enesetõhusus & 0,38 & $3,18^{* *}$ & & \\
\hline Samm 3 & & & 0,21 & 0,07 \\
\hline Jäävususkumus & 0,25 & $2,15^{*}$ & & \\
\hline Enesetõhusus & 0,42 & $3,38^{* *}$ & & \\
\hline Erialahuvi & $-0,14$ & $-1,12$ & & \\
\hline Samm 4 & & & 0,26 & 0,05 \\
\hline Jäävususkumus & 0,29 & $2,48^{*}$ & & \\
\hline Enesetõhusus & 0,34 & $2,74^{* *}$ & & \\
\hline Erialahuvi & $-0,19$ & $-1,53$ & & \\
\hline Vähene pingutuse suunamine & $-0,26$ & $-2,10^{*}$ & & \\
\hline
\end{tabular}

Märkus. ${ }^{*}-p<0,05 ;{ }^{* *}-p<0,01$.

Et hinnata, kas sekkumis- ja kontrollrühm üksteisest enne sekkumist liialt ei erinenud, tehti kõigi hinnatud tunnuste kohta rühmiti võrdlev dispersioonanalüüs (ANOVA), mis näitas sekkumiseelset rühmadevahelist statistiliselt olulist erinevust vaid erialahuvi puhul $\left(F(1,78)=10,15, p=0,00, \eta^{2}=0,12\right.$; $M=4,58, S D=0,51$ sekkumisrühmas ja $M=4,20, S D=0,56$ kontrollrühmas).

Sügissemestri reaalainete keskmiste hinnete võrdlemisel ilmnes, et kontrollrühma tulemused on oluliselt paremad kui sekkumisrühma üliõpilaste omad $\left(F(1,61)=24,84, p=0,00, \eta^{2}=0,29 ; M=2,57, S D=1,08\right.$ sekkumisrühmas ja $M=3,73, S D=0,74$ kontrollrühmas). 


\section{Sekkumise mõju ja rühmadevahelised erinevused kahe testimiskorra võrdluses}

Et hinnata sekkumise mõju, tehti iga tunnuse kohta kordusmõõtmistega kahesuunaline dispersioonanalüüs. Tulemused (vt tabel 4) näitasid statistiliselt olulist aja ja sekkumise koosmõju kahe tunnuse puhul: jäävususkumus võimekuse muudetavuse kohta $\left(F(1,61)=4,70, p<0,05, \eta^{2}=0,07\right)$ ja vähene pingutuse suunamine $\left(F(1,61)=8,26, p<0,01, \eta^{2}=0,12\right)$.

Tabel 4. Hinnatud tunnuste kirjeldavad statistikud sekkumisperioodi eel ja järel ning kordusmõõtmistega kahesuunalise dispersioonanalüüsi tulemused

\begin{tabular}{|c|c|c|c|c|c|c|c|}
\hline Tunnus & Rühm & $N_{\text {eeltest }}$ & $N_{\text {järeltest }}$ & $M(S D)_{\text {eeltest }}$ & $M(S D)_{\text {järeltest }}$ & $F$ & $n^{2}$ \\
\hline \multirow{2}{*}{$\begin{array}{l}\text { Jäävususkumus } \\
\text { vaimse võimekuse } \\
\text { muudetavuse } \\
\text { kohta }\end{array}$} & $x$ & 46 & 37 & $2,53(0,65)$ & $2,13(0,64)$ & \multirow[b]{2}{*}{$4,7^{*}$} & \multirow[b]{2}{*}{0,07} \\
\hline & Y & 34 & 26 & $2,56(0,82)$ & $2,47(0,83)$ & & \\
\hline \multirow{2}{*}{$\begin{array}{l}\text { Akadeemiline } \\
\text { enesetõhusus }\end{array}$} & $x$ & 46 & 37 & $3,64(0,69)$ & $3,53(0,77)$ & \multirow{2}{*}{3,32} & \multirow{2}{*}{0,05} \\
\hline & Y & 34 & 26 & $3,47(0,61)$ & $3,77(0,72)$ & & \\
\hline \multirow[t]{2}{*}{ Erialahuvi } & $x$ & 46 & 37 & $4,58(0,51)$ & $4,54(0,58)$ & \multirow{2}{*}{0,24} & \multirow{2}{*}{0,00} \\
\hline & $Y$ & 34 & 26 & $4,20(0,56)$ & $4,23(0,52)$ & & \\
\hline \multirow{2}{*}{$\begin{array}{l}\text { Vähene pingutuse } \\
\text { suunamine }\end{array}$} & $x$ & 46 & 37 & $1,88(0,66)$ & $2,41(0,80)$ & \multirow{2}{*}{$8,26^{*}$} & \multirow{2}{*}{0,12} \\
\hline & Y & 34 & 26 & $2,16(0,67)$ & $2,13(0,69)$ & & \\
\hline
\end{tabular}

Märkus. ${ }^{*}-p<0,05$.

Sekkumisrühmas vähenes kontrollrühmaga võrreldes oluliselt kalduvus jäävususkumusele võimekuse muudetavuse kohta, mis näitab, et sekkumisrühma üliõpilaste seas kasvas usk vaimse võimekuse muudetavusse. Pingutuse suunamisel vähenes just sekkumisrühma valmisolek pingutada, samas kui kontrollrühma tulemus ei muutunud.

\section{Arutelu}

Õpimotivatsiooniga seotud tegurid ja eneseregulatsioonioskused on õpingute edenemisel tähtsad ning seepärast on otstarbekas õpiprotsessis nende osakomponente teadlikult hinnata ja toetada (Pintrich \& De Groot, 1990; Seymour \& Hewitt, 1997; Talsma et al., 2018). Ka spetsiifiliselt inseneriteaduse õppekavade üliõpilaste seas tehtud uuringud on näidanud, et motivatsioonitegurid on tihedalt seotud õpingute tulemuslikkusega (Dai \& Cromley, 2014; Mamaril, 2014; 
Seymour \& Hewitt, 1997) ning just esimese õppeaasta õpikogemusel on määrav roll selles, kas õpinguid jätkatakse või need katkestatakse (Hunt, 2011).

Eeltoodut arvesse võttes seati uurimuse eesmärgiks analüüsida Tallinna Tehnikakõrgkooli esimese kursuse üliõpilaste implitsiitsete võimekususkumuste ja teiste kirjanduse põhjal oluliste motivatsioonitegurite koosmõju reaalainetes edasijõudmise ennustajana ning hinnata, kas hüpoteesis esitatud väited leiavad kinnitust ka inseneriteaduse üliõpilaste testimisel. Kuna varem on ilmnenud, enamasti küll põhikooli kontekstis, et tegu on pädevustega, mida on võimalik õpikeskkonnas toetada ja arendada (Blackwell et al., 2007; Paunesku et al., 2015), uuriti ühtlasi, kas lühiajalise, kuid fookustatud sekkumisega (nn arukas sekkumine, vt Walton, 2014) on võimalik mõjutada üliõpilaste mõtteviisi juurdekasvuuskumuste suunas.

Püstitatud hüpoteesid leidsid vaid osalist kinnitust. Oodatult ilmnes, et kõrgkooli esimese kursuse inseneriõppe üliõpilaste jäävususkumused ja vähene pingutuse suunamine ennustavad halvemat ning suurem akadeemiline enesetõhusus paremat edasijõudmist reaalainetes. Erialahuvi roll reaalainete tulemuste ennustamisel kinnitust ei leidnud. On huvitav, et erialahuvi, mida on nii kõrgkoolist väljalangemist kajastavate sotsioloogiliste uuringute (Espenberg et al., 2014) kui ka tehnikakõrgkoolis tehtud kvaliteediuuringute tulemusi arvestades peetud üheks oluliseks õpitee kujunemisega seotud teguriks ning mida nimetavad ka üliõpilased ise retrospektiivselt üle veerandil juhtudest õpingute katkestamise peamise põhjusena, ei seostunud statistiliselt olulisel määral ei muude motivatsiooniteguritega ega ka õpitulemustega reaalainetes. Küll aga selgus sekkumis- ja kontrollrühma võrdluses, et mõlema rühma erialahuvi säilis suhteliselt stabiilsena terve uuringu vältel. Seega võib spekuleerida, et erialasobimatus, mida üliõpilased märkisid õpingute katkestamise põhjusena, ei pruugi alati olla lõpuni usaldusväärne indikaator, eriti kui õpingute alguses on inseneriteaduse õppekavades rõhk üld- ja alusainetel, millel ei pruugi olla selget ja otsest seost eriala põhiainete ega praktikaga.

Uurimistulemus, et nii implitsiitsed jäävususkumused, akadeemiline enesetõhusus kui ka soov või soovimatus keeruliste ülesannete puhul pingutada olid reaalainete õpitulemuste olulised ennustajad, toetab üldhariduse kontekstis saadud varasemaid uurimistulemusi (vt nt Blackwell et al., 2007), viidates sellele, et õppimisega seotud uskumuste ja õpikäitumise teadvustamisega tuleb tegelda kõigil haridusastmetel. Paraku on ka enesereguleeritud õppimise toetamist uurides osutatud, et vaid vähesed koolitajad analüüsivad õppijate õppimisega seotud uskumusi, hoiakuid ja õpistrateegiate valikuid enne, kui kognitiivsed ja motivatsiooniprobleemid hakkavad mõjutama õppimises edasijõudmist (Zimmerman, 2002). 
Uuringu raames tehtud sekkumise eesmärgiks seati sekkumisrühma üliõpilaste implitsiitsete võimekususkumuste mõjutamine juurdekasvuuskumuste suunas. Eeldati, et lühiajalise sekkumisega, mis on tõendatud teaduspõhine vahend muutuse esilekutsumiseks teatud laadi mõtte- või käitumisviisis, õnnestub mõjutada õppijate arusaama õppimisest kui pingutust nõudvast protsessist, mille puhul on tähtis teadvustada nii vigade tegemise olulisust kui ka vajadust pöörata tähelepanu tagasilöökidega kaasnevatele emotsioonidele ja kasutada vajaduse korral muid õpistrateegiaid. Tulemused viitavad sekkumise tulemuslikkusele implitsiitsete võimekususkumuste puhul. Sekkumisrühmas kasvas teadlikkus akadeemiliste võimete arendatavusest. Kontrollrühmas muutust ei täheldatud. Sekkumise fookustatud mõjust annab tunnistust ka tõsiasi, et võimekususkumustega mitte seostuv erialahuvi jäi nii sekkumis- kui ka kontrollrühmas samale tasemele ning ka enesetõhusus ei näidanud kummaski rühmas statistiliselt olulisi muutumismärke. Huvitava tulemusena ilmnes oodatust vastupidine efekt pingutuse suunamisel. Nimelt vähenes sekkumisrühma kuulunud üliõpilaste soov keeruliste ülesannete korral pingutada, samas kui kontrollrühmas jäi see näitaja samale tasemele. Saadud tulemust võib küll mõnevõrra seletada õpperühmade erineva akadeemilise edasijõudmisega reaalainetes, kuid selline seletus on spekulatiivse iseloomuga ning vajaks lisauurimist.

Üks seletus, miks andsid sekkumisrühma üliõpilaste keskmised hinded reaalainetes tunnistust kehvemast akadeemilisest edasijõudmisest, võib olla seotud sellega, et need üliõpilased võisid tunnetada sügissemestri viimasel kolmandikul ehk teise andmekorje ajal suuremat stressi seoses keeruliste või üle jõu käivate õpiülesannete kuhjumisega (lähenev semestri lõpp toob endaga kaasa mahukad kodu- ja arvestustööd), mis omakorda võis olla õpimotivatsiooni vähenemise põhjus. Sarnastele ilmingutele viitavad oma uurimuses ka Spitzer ja Aronson (2015). Võimalik, et peale juurdekasvumõttelaadi teadvustamise peaks reaalses pingutuskäitumises soovikohast muutust esile kutsuv sekkumine olema ka käitumuslikult selgemalt fookustatud ning pingutamise olulisust õppimise vältimatu osana tuleks veelgi enam rõhutada (Sun, 2015). Niisamuti on võimalik, et tõhus sekkumine peaks olema pikemaajalisem, sest sügavamate uskumuste või elu jooksul kogutud tõekspidamiste korrigeerimine ning muutuste käitumuslik avaldumine vajavad aega (Dommett, Devonshire, Sewter, \& Greenfield, 2013).

Tulemuste tõlgendamisel tuleb arvestada, et sekkumine ei suutnud piisavalt ennetada probleeme, mis võisid olla tingitud sügissemestril kumuleeruvalt mõju avaldanud varasematest probleemidest. Ehkki uuringud viitavad, et õppijate mõtteviisi toetamine juurdekasvuuskumuste suunas toob kõige rohkem kasu neile õppuritele, kelle õppetöös edasijõudmise näitajad on pigem kasinad 
või keda on mõtteliselt paigutatud halvemate saavutustega õppijate riskirühma (Paunesku et al., 2015), ei õnnestunud siinses uuringus pingutuse suunamisel sama mõju näidata, vähemasti mitte uuritavas ajaraamis ja lühiaegse sekkumise korral. Seega leidis kinnitust oletus, et implitsiitseid võimekususkumusi käsitleva sekkumisega on võimalik mõjutada tehnikavaldkonna üliõpilaste implitsiitseid võimekususkumusi juurdekasvuuskumuste suunas, kuid sekkumisrühma üliõpilaste pingutuskäitumise paranemist sekkumisuuring ei kinnitanud.

Tehtud uuringul oli mõningaid piiranguid. Õppekavade kaasamisel valimisse lähtuti tagasiulatuvatest keskmistatud andmetest väljalangemuse kohta, kuid on selge, et iga järgmine vastuvõtt sama õppekava alusel on variatiivse iseloomuga ning uuringus osalevad üliõpilased ei pruugi varasemate aastate edasijõudmise või väljalangemuse trende kinnitada. Seega tuleb silmas pidada, et võrreldavad õppekavad ei pruukinud uuringu aja taustategurite poolest eeldataval määral sarnaneda. Lisaks väärib mainimist, et ehkki uuringus kasutati pikiuuringu tunnustega sekkumisuuringut, ei võimalda uuringu korraldus siiski analüüsida põhjuslikke seoseid uuritud tegurite vahel. Samuti tuleb rõhutada, et järeldused tuginevad enesekohaste küsimustike andmetele ning valiidsemate järelduste tegemiseks tuleks protsesse hinnata ka käitumuslikult.

Tulemused viitavad mõningatele aspektidele, mis vajaksid edasist uurimist. Esiteks, kuna just sekkumisrühmas vähenes soov keeruliste ülesannete puhul pingutada, kuid kontrollrühmas püsisid tulemused stabiilsed või pigem isegi paranesid, võib oletada, et kontrollrühma stabiilsena püsinud pingutusvõime taga on mitmekesisem õpistrateegiate kasutamise oskus ning püsiv motivatsioon õppida valitud erialal, kuid seda hüpoteesi tuleks edasi uurida. Teiseks tuleb tähelepanu pöörata asjaolule, et autoritel puudusid andmed valimisse kuulunud üliõpilaste varasemate õpitulemuste kohta, millega õppimises edasijõudmist sekkumise järel võrrelda, mistõttu tuleks peale võimekust puudutavate arusaamade teadvustamise edaspidi hinnata ka sekkumise mõju reaalsele õpikäitumisele. Kolmandaks, implitsiitsete võimekususkumuste teooriat on empiiriliselt palju uuritud ning tegu on tõenduspõhise lähenemisega õpikäitumise mõtestamisele (Rattan et al., 2015; Yeager \& Walton, 2011). Siiski on jätkuv vajadus leida haridusprobleemide leevendamiseks püsivaid lahendusi, mille korral on tuginetud tõenduspõhistele sotsiaalpsühholoogilistele, kohalikust kontekstist lähtuvatele ja osaliste jaoks tähenduslikele sekkumisuuringutele, mis ei ole mõeldud haridusreforme asendama, küll aga parandama selliste reformide kvaliteeti (Yeager \& Walton, 2011).

Siinne uurimistöö tõendas, et lühike, kuid metoodiliselt läbimõeldud sekkumine inseneriteaduse üliõpilastele juurdekasvuuskumuste õpetamisel tõi kaasa positiivsed muutused õppijate arusaamades võimekuse olemuse kohta. Kuna 
esimene õppeaasta kõrgkoolis võib saada õpingute jätkamise või katkestamise oluliseks verstapostiks (Hunt, 2011), on vaja luua juba õpingute algusfaasis õppimiseks keskkond, mis toetab peale õpihuvi teadlikult ka õppijate arusaama õppimisprotsessist ja õpioskuseid. Kõrgharidusõppeski ei saa eeldada, et kõik õppijad on ennastjuhtivad ning neil on olemas kõrgharidusõppes toimetulekuks vajalikud hoiakud, teadmised ja oskused. Aineteadmiste esitamise kõrval peab ka sellel haridusastmel jätkuvalt tähelepanu pöörama ópioskuste arendamisele. Väljalangemust aitab ennetada ka märkamine: määrava tähtsusega on sellise õppija märkamine, kelle arusaamad võimekuse arendatavusest ja tõhusatest õppimisviisidest ei toeta tema akadeemilist arengut ning seega pärsivad tema tahet edasi õppida. Et potentsiaalselt riskirühma kuuluvad õppijad ei jääks märkamata ja seega õigel ajal toetamata, on ka kõrgharidustasemel tarvis arendada välja tõenduspõhiseid seire- ja toetusprogramme. Samuti peab püsiva muutuse ellukutsumiseks õppeprotsessis toetama arengut ja õppimist soodustavaid uskumusi organisatsiooni tasandil süsteemselt, hõlmates muu hulgas arendusprogramme, mis toetavad õppejõudude õpetamis- ja õppimisalaste teaduspõhiste teadmiste omandamist.

\section{Tänusõnad}

Täname uuringus osalenud Tallinna Tehnikakõrgkooli üliõpilasi.

\section{Kasutatud kirjandus}

Aronson, J., Fried, C. B., \& Good, C. (2002). Reducing the effects of stereotype threat on African American college students by shaping theories of intelligence. Journal of Experimental Social Psychology, 38(2), 113-125. https://doi.org/10.1006/jesp.2001.1491

Aus, K., Jõgi, A.-L., Poom-Valickis, K., Eisenschmidt, E., \& Kikas, E. (2017). Associations of newly qualified teachers' beliefs with classroom management practices and approaches to instruction over one school year. European Journal of Teacher Education, 40(1), 28-45. https://doi.org/10.1080/02619768.2016.1251897

Baker, D. R., Wood, L., Corkins, J., \& Krause, S. (2015). Tinkering and technical selfefficacy of engineering students at the community college. Community College Journal of Research and Practice, 39(6), 555-567. https://doi.org/10.1080/10668926.2014.902780

Bandura, A. (1986). Fearful expectations and avoidant actions as coeffects of perceived self-inefficacy. American Psychologist, 41(12), 1389-1391.

https://doi.org/10.1037/0003-066X.41.12.1389 
Blackwell, L. S., Trzesniewski, K. H., \& Dweck, C. S. (2007). Implicit theories of intelligence predict achievement across an adolescent transition: A longitudinal study and an intervention. Child Development, 78(1), 246-263. https://doi.org/10.1111/j.1467-8624.2007.00995.x

Burnette, J. L., O’Boyle, E. H., VanEpps, E. M., Pollack, J. M., \& Finkel, E. J. (2013). Mind-sets matter: A meta-analytic review of implicit theories and self-regulation. Psychological Bulletin, 139(3), 655-701. https://doi.org/10.1037/a0029531

Dai, T., \& Cromley, J. G. (2014). Changes in implicit theories of ability in biology and dropout from STEM majors: A latent growth curve approach. Contemporary Educational Psychology, 39(3), 233-247. https://doi.org/10.1016/j.cedpsych.2014.06.003

Dekker, G. W., Pechenizkiy, M., \& Vleeshouwers, J. M. (2009). Predicting students drop out: A case study. In T. Barnes, M. Desmarais, C. Romero, \& S. Ventura (Eds.), Proceedings of the 2nd International Conference on Educational Data Mining, EDM 2009, July 1-3, 2009. Cordoba, Spain (pp. 41-50). Retrieved from https://pure.tue.nl/ws/files/2813648/Metis233712.pdf.

Dommett, E. J., Devonshire, I. M., Sewter, E., \& Greenfield, S. A. (2013). The impact of participation in a neuroscience course on motivational measures and academic performance. Trends in Neuroscience and Education, 2(3-4), 122-138. https://doi.org/10.1016/j.tine.2013.05.002

Dweck, C. (2015a). Carol Dweck revisits the 'Growth Mindset'. Education Week, 35(5), 20-24. Retrieved from https://www.edweek.org/ew/articles/2015/09/23/ carol-dweck-revisits-the-growth-mindset.html.

Dweck, C. (2015b). “The Growth Mindset”. Talks at Google. Retrieved from https://www.youtube.com/watch?v=-71zdXCMU6A\&t=1718s.

Dweck, C. S., Chiu, C. Y., \& Hong, Y. Y. (1995). Implicit theories and their role in judgments and reactions: A word from two perspectives. Psychological Inquiry, 6(4), 267-285. https://doi.org/10.1207/s15327965pli0604_1

Dweck, C. S., \& Leggett, E. L. (1988). A social-cognitive approach to motivation and personality. Psychological Review, 95(2), 256-273. https://doi.org/10.1037/0033-295X.95.2.256

Eris, O., Chachra, D., Chen, H. L., Sheppard, S., Ludlow, L., Rosca, C., ... Toye, G. (2010). Outcomes of a longitudinal administration of the persistence in engineering survey. Journal of Engineering Education, 99(4), 371-395. https://doi.org/10.1002/j.2168-9830.2010.tb01069.x

Espenberg, K., Aksen, M., Beilmann, M., Vahaste, S., Loogus, T., \& Kührt, U. (2014). Kõrgkooliõpingute katkestamise põhjused ja ennetamise võimalused Euroopa Liidu riikide näitel. Lõpparuanne. Külastatud aadressil https://www.digar.ee/arhiiv/nlib-digar:220931.

Haridussilm (s. a.). Külastatud aadressil https://www.haridussilm.ee/.

Heslin, P. A., \& VandeWalle, D. (2008). Managers' implicit assumptions about personnel. Current Directions in Psychological Science, 17(3), 219-223. https://doi.org/10.1111/j.1467-8721.2008.00578.x

Heublein, U., \& Schmelzer, R. (2018). Die Entwicklung der Studienabbruchquoten an den deutschen Hochschulen: Berechnungen auf Basis des Absolventenjahrgangs 2016. Hannover: Deutsches Zentrum für Hochschul- und Wissenschaftforschung. https://idw-online.de/en/attachmentdata66127.pdf. 
Hunt, C. (2011). National strategy for higher education to 2030. Report of the Strategy Group. Retrieved from http://hea.ie/assets/uploads/2017/06/National-Strategyfor-Higher-Education-2030.pdf.

Jõgi, A-L., \& Aus, K. (2015). Õpipädevus. E. Kikas \& A. Toomela (toim.), Õppimine ja ópetamine kolmandas kooliastmes. Üldpädevused ja nende areng (lk 112-146). Tallinn: Tallinna Ülikool. Külastatud aadressil https://www.hm.ee/sites/default/files/oppimine_ja_opetamine_3_kooliastmes.pdf.

Koenig, K., Schen, M., Edwards, M., \& Bao, L. (2012). Addressing STEM retention through a scientific thought and methods course. Journal of College Science Teaching, 41(4), 23-29.

Kok, G., Gottlieb, N. H., Peters, G.-J. Y., Mullen, P. D., Parcel, G. S., Ruiter, R. A. C., ... Bartholomew, L. K. (2016). A taxonomy of behaviour change methods: An intervention mapping approach. Health Psychology Review, 10(3), 297-312. https://doi. org/10.1080/17437199.2015.1077155

Li, Q., McCoach, D. B., Swaminathan, H., \& Tang, J. (2008). Development of an instrument to measure perspectives of engineering education among college students. Journal of Engineering Education, 97(1), 47-56. https://doi.org/10.1002/j.2168-9830.2008.tb00953.x

Mamaril, N. J. A. (2014). Measuring undergraduate students' engineering self-efficacy: A scale validation study (Doctoral dissertation). Lexington: University of Kentucky. Retrieved from https://uknowledge.uky.edu/cgi/viewcontent.cgi?article=1020\&context=edp_etds.

Marsh, H. W., \& Yeung, A. S. (1998). Longitudinal structural equation models of academic self-concept and achievement: Gender differences in the development of math and English constructs. American Educational Research Journal, 35(4), 705738. https://doi.org/10.2307/1163464

Meyer, M. (2015). Persistence of engineering undergraduates at a public research university (Doctoral dissertation). Logan: Utah State University. Retrieved from https://digitalcommons.usu.edu/cgi/viewcontent.cgi?article=5302\&context=etd.

Meyer, M., \& Marx, S. (2014). Engineering dropouts: A qualitative examination of why undergraduates leave engineering. Journal of Engineering Education, 103(4), 525-548. https://doi.org/10.1002/jee.20054

Mueller, C. M., \& Dweck, C. S. (1998). Praise for intelligence can undermine children's motivation and performance. Journal of Personality and Social Psychology, 75(1), 33-52. https://doi.org/10.1037/0022-3514.75.1.33

Paunesku, D., Walton, G. M., Romero, C., Smith, E. N., Yeager, D. S., \& Dweck, C. S. (2015). Mind-set interventions are a scalable treatment for academic underachievement. Psychological Science, 26(6), 784-793. https://doi.org/10.1177/0956797615571017

Pekrun, R., Goetz, T., Titz, W., \& Perry, R. P. (2002). Academic emotions in students' self-regulated learning and achievement: A program of qualitative and quantitative research. Educational Psychologist, 37(2), 91-105.

https://doi.org/10.1207/S15326985EP3702_4

Pintrich, P. R., Smith, D. A. F., Garcia, T, \& McKeachie, W. J. (1991). A manual for the use of the Motivated Strategies for Learning Questionnaire (MSLQ). Ann Arbor: The University of Michigan. Retrieved from https://files.eric.ed.gov/fulltext/ED338122.pdf. 
Pintrich, P. R., \& De Groot, E. V. (1990). Motivational and self-regulated learning components of classroom academic performance. Journal of Educational Psychology, 82(1), 33-40. https://doi.org/10.1037/0022-0663.82.1.33

Quinn, J. (2013). Drop-out and completion in higher education in Europe among students from under-represented groups. An independent report authored for the European Commission. Retrieved from https://nesetweb.eu/wp-content/uploads/ 2019/06/2013-Drop-out-and-Completion-in-Higher-Education-in-Europeamong-students-from-under-represented-groups.pdf.

Rattan, A., Savani, K., Chugh, D., \& Dweck, C. S. (2015). Leveraging mindsets to promote academic achievement: Policy recommendations. Perspectives on Psychological Science, 10(6), 721-726. https://doi.org/10.1177/1745691615599383

Richardson, M., Abraham, C., \& Bond, R. (2012). Psychological correlates of university students' academic performance: A systematic review and meta-analysis. Psychological Bulletin, 138(2), 353-387. https://doi.org/10.1037/a0026838

Schommer-Aikins, M., Mau, W.-C., Brookhart, S., \& Hutter, R. (2000). Understanding middle students' beliefs about knowledge and learning using a multidimensional paradigm. The Journal of Educational Research, 94(2), 120-127. https://doi.org/10.1080/00220670009598750

Seymour, E., \& Hewitt, N. M. (1997). Talking about leaving: Why undergraduates leave the sciences. Boulder: Westview Press.

Spitzer, B., \& Aronson, J. (2015). Minding and mending the gap: Social psychological interventions to reduce educational disparities. British Journal of Educational Psychology, 85(1), 1-18. https://doi.org/10.1111/bjep.12067

Suhre, C. J., Jansen, E. P., \& Harskamp, E. G. (2007). Impact of degree program satisfaction on the persistence of college students. Higher Education, 54(2), 207-226. https://doi.org/10.1007/s10734-005-2376-5

Sun, K. L. (2015). There's no limit: Mathematics teaching for a growth mindset (Doctoral dissertation). Stanford: Stanford University. Retrieved from https://stacks. stanford.edu/file/druid:xf479cc2194/Sun-Dissertation-Upload-augmented.pdf.

Zimmerman, B. J. (2002). Becoming a self-regulated learner: An overview. Theory into Practice, 41(2), 64-70. https://doi.org/10.1207/s15430421tip4102_2

Talsma, K., Schüz, B., Schwarzer, R., \& Norris, K. (2018). I believe, therefore I achieve (and vice versa): A meta-analytic cross-lagged panel analysis of self-efficacy and academic performance. Learning and Individual Differences, 61, 136-150. https://doi.org/10.1016/j.lindif.2017.11.015

Valentine, J. C., DuBois, D. L., \& Cooper, H. (2004). The relation between self-beliefs and academic achievement: A meta-analytic review. Educational Psychologist, 39(2), 111-133. https://doi.org/10.1207/s15326985ep3902_3

Vinter, K., Aus, K., \& Arro, G. (2019). Eesti ja vene õppekeelega põhikooliõpilaste akadeemiline läbipõlemine. Eesti Haridusteaduste Ajakiri, 7(1), 128-156. https://doi.org/10.12697/eha.2019.7.1.06

Walton, G. M. (2014). The new science of wise psychological interventions. Current Directions in Psychological Science, 23(1), 73-82. https://doi.org/10.1177/0963721413512856

Wilson, Z. S., Holmes, L., deGravelles, K., Sylvain, M. R., Batiste, L., Johnson, M., ... \& Warner, I. M. (2012). Hierarchical mentoring: A transformative strategy for 
improving diversity and retention in undergraduate STEM disciplines. Journal of Science Education and Technology, 21(1), 148-156.

https://doi.org/10.1007/s10956-011-9292-5.

Wolters, C. A. (1998). Self-regulated learning and college students' regulation of motivation. Journal of Educational Psychology, 90(2), 224-235.

https://doi.org/10.1037/0022-0663.90.2.224

Üliõpilaste õpingute katkestamiste põhjused ja võimalikud meetmed õpingutes edasijõudmise toetamiseks üheksa rakenduskõrgkooli näitel (2015). Haridus- ja Teadusministeerium, Euroopa Sotsiaalfond. Külastatud aadressil https://www.tktk.ee/ wp-content/uploads/\%C3\%9Cli\%C3\%B5pilaste-\%C3\%B5pingute-katkestamiseuuring.pdf2015.pdf.

Yeager, D. S., \& Dweck, C. S. (2012). Mindsets that promote resilience: When students believe that personal characteristics can be developed. Educational Psychologist, 47(4), 302-314. https://doi.org/10.1080/00461520.2012.722805

Yeager, D. S., Romero, C., Paunesku, D., Hulleman, C. S., Schneider, B., Hinojosa, C., ... Trott, J. (2016). Using design thinking to improve psychological interventions: The case of the growth mindset during the transition to high school. Journal of Educational Psychology, 108(3), 374-391. https://doi.org/10.1037/edu0000098

Yeager, D. S., \& Walton, G. M. (2011). Social-psychological interventions in education: They're not magic. Review of Educational Research, 81(2), 267-301.

https://doi.org/10.3102/0034654311405999 


\title{
More efficient engineering education through supporting implicit ability beliefs
}

\author{
Britt Petjärv $^{\mathrm{a} 1}$, Kati Aus ${ }^{\mathrm{b}}$, Grete Arro \\ ${ }^{a}$ Centre for Humanities and Economics, TTK University of Applied Sciences \\ ${ }^{b}$ School of Educational Sciences, Tallinn University
}

\section{Summary}

\section{Introduction}

According to labour market statistics the shortage of engineers is a serious problem in Estonia. Unfortunately, when studying drop out from higher education institutions, it appears that undergraduate drop out is one of the highest in the field of technology (www.haridussilm.ee) and the drop-out rate of first year engineering students is the most problematic (Dekker et al., 2009; Haridussilm, s. a.). The study of university drop-out levels has revealed that interruption of studies is a multi-faceted phenomenon which, as a rule, is the result of various concurrent reasons: wrong choice of specialty, academic failure, low sense of belonging and relatedness, studies not corresponding to personal abilities, etc. (Espenberg et al., 2014).

In addition to interest in speciality (Mamaril, 2014), contentment with curriculum structure (Suhre et al., 2007), academic self-efficacy (Talsma et al., 2018), and effort regulation (Richardson et al., 2012) that have been traditionally regarded as important predictors of academic success, students' views about the malleability of intellectual ability (intelligence beliefs) are also considered as a significant aspect of study motivation and learning behaviour (Burnette et al., 2013). Although the role of implicit beliefs of ability as a study progress indicator has science-based proof (ibid.) and the relevance of ability beliefs has been acknowledged in the context of elementary school also in Estonia (Aus et al., 2017; Vinter et al., 2019), it has so far not been widely applied in the analyses reflecting the academic progress of Estonian students at higher levels of education.

The present work focuses on implicit beliefs of ability (Dweck \& Leggett, 1988) in order to enrich the methodology currently used to analyse factors shaping the learning paths of university students in Estonia. To the knowledge of the authors this focus has previously received little or no attention in the

Centre for Humanities and Economics, TTK University of Applied Sciences, Pärnu mnt 62, 10135 Tallinn, Estonia; britt.petjarv@tktk.ee 
higher education context in Estonia. The aim is to analyse how do students' implicit ability beliefs and other motivational factors that have been included in the study - academic self-efficacy, interest in speciality and effort regulation -interact in predicting students' academic achievement. Studies show that supporting a growth mindset towards intellectual ability improves the learners' progress in mathematics (Blackwell et al., 2007) and that implicit beliefs of ability of engineering students have an impact on their progress in engineering studies (Dai \& Cromley, 2014).

In the context of a professional higher education institution it will be examined, whether it is possible to change learners' implicit ability beliefs with a short seminar-intervention towards a growth mindset as shown with different interventions in the elementary school (Blackwell et al., 2007; Paunesku et al., 2015).

Based on the described research the following hypotheses have been set:

1) The fixed mindset and low effort regulation of the first-year students of TTK UAS predict lower progress in science subjects while higher academic self-efficacy and speciality interest indicate better progress in science subjects.

2) It is possible to bring about positive changes in engineering students' implicit ability beliefs and effort regulation with an intervention that addresses ability beliefs.

\section{Methodology}

In order to test the hypothesis, a study instrument in the form of a questionnaire, was first drawn up. It covered the aspects related to the above-mentioned beliefs, learning motivation and study behaviour. To evaluate the validity of subscales, or in order to assess whether the devised instrument is suitable for measuring the beliefs and learning motivation of the students in the field of technical higher education, the questionnaire was piloted before the intervention study. The general sample included 270 students from ten different curricula of TTK UAS.

An experimental intervention study (2 two-hour seminars on implicit ability beliefs and neuroplasticity together with pre-and post-seminar assignments) was carried out among first-year students $(N=37)$ of a curriculum at TTK UAS (conditionally named as Curriculum $X$ ) aimed at influencing the students' beliefs towards a growth mindset. The students in the sample were interviewed twice using identical questionnaires: before the intervention (October 2017) and after the intervention (November 2017). The first-year students in Curriculum $Y$ from the same institution participated in the study as a control 
group. The students in the control group, who did not receive the intervention, were likewise assessed twice (in October and November). The academic progress indicators (the average mark in science subjects of the autumn semester 2017) were included in the further analyses.

\section{Results and conclusions}

Hierarchical regression analysis was used in order to assess which aspects of study motivation and behaviour were significant in explaining the variance in students' performance in the science disciplines. Academic self-efficacy $(\beta=.34, p<.01)$, fixed ability beliefs $(\beta=.22, p<.05)$ and low effort regulation $(\beta=-.26, p<.05)$ were the strongest predictors of grades in the science subjects among the factors studied. Interest did not predict variance in grades. In order to evaluate the effect of the intervention, a repeated measures two-way ANOVA was carried out for every construct. The results showed a significant interaction of time and intervention for two constructs: ability beliefs and effort regulation.

The hypotheses were only partially verified. As expected, first year engineering students' fixed ability beliefs and lower levels of effort regulation predict worse, and higher academic self-efficacy and speciality interest predict better academic achievement in the science subjects. It is interesting that students generally report a lack of speciality interest as the main reason for quitting their studies, and it has been regarded as one of the defining factors shaping the educational path of students both in sociological studies covering drop out from higher education (Espenberg et al., 2014) as well as in quality studies carried out by the applied university itself. However, the present study revealed that the speciality interest was not significantly associated with either other motivational factors or performance in the science subjects.

The result that implicit ability beliefs, academic self-efficacy and low effort regulation played a significant role in predicting grades in science subjects, supports earlier results from the basic level education (e.g., Blackwell et al., 2007), being a clear indication that addressing beliefs associated with learning is important at all levels of education.

The intervention carried out in the study showed that growing awareness about the malleability of academic abilities was witnessed in the intervention group, a change that was not evident in the control group. The targeted effect of the intervention is further supported by the fact that speciality interest and self-efficacy that are not directly linked to implicit beliefs of ability, showed no significant changes neither in the control nor the intervention group. An opposite than expected result appeared concerning effort regulation. In particular, the desire of students belonging to the intervention group to perform difficult 
tasks fell, while in the control group the corresponding figure remained at the same level. Although the result may be somewhat explained by the different academic advancement of study groups in science subjects, these explanations are speculative and would require further study. At the same time, it is also possible that the intervention was not able to adequately prevent problems which may have been caused by other underlying issues, which had an accumulative effect during the autumn semester. On the basis of the above, we note that the assumption was confirmed that by the intervention of implicit ability beliefs, it is possible to influence the implicit ability beliefs of students in the technical field towards growth mindset, but in order to bring about a lasting change in the level of the learning process, support for development-oriented and learning-enhancing beliefs must be systematic to the level of the organisation, including, inter alia, development programmes that support the acquisition of scientific knowledge regarding teaching and learning among lecturers.

Keywords: implicit ability beliefs, fixed mindset, growth mindset, motivation, academic achievement in engineering, intervention study 